\title{
El concepto de trabajo: perspectiva histórica*
}

\section{The Concept of Work: Historical Perspective}

\author{
Laura Andrea Cristancho Giraldo ${ }^{* *}$ \\ (D) https://orcid.org/0000-0002-6273-7863 \\ Politécnico Grancolombiano, Bogotá, Colombia. \\ lcristancho@poligran.edu.co
}

Resumen: A partir de un reconocimiento del significado de trabajo en la historia del hombre, el presente artículo expone las diferentes maneras como se ha concebido el trabajo desde la profunda transformación de las sociedades campesinas a las ciudades levemente industrializadas con las que culminó la Edad Media, dando así inicio a la denominada Modernidad; el hito histórico del descubrimiento de América con los grandes contrastes de una sociedad avanzada y unos grupos indígenas con sus saberes ancestrales propios de sus culturas nativas, que lentamente se vieron obligados a adaptar sus saberes a los de sus colonizadores y en algunos casos conquistadores, hasta el pensamiento contemporáneo en donde el trabajo intelectual cobra especial fuerza y valor social y, finalmente, es expuesto el concepto de trabajo en Latinoamérica hasta finales del siglo $\mathrm{xx}$.

* Este artículo es derivado de un capítulo de contextualización histórica de la tesis doctoral Pertinencia de la política económica en materia de generación de empleo "decente" en la ciudad de Bogotá, Colombia, Universidad Nacional de Educación a Distancia, España.

** Doctora en Análisis de Problemas Sociales. Docente de tiempo completo en el programa de Economía en Politécnico Grancolombiano, Bogotá, Colombia. Línea de investigación: mercado laboral, sociología del trabajo.

Cómo citAR: Cristancho Giraldo, L. A. (2022). El concepto de trabajo: perspectiva histórica. Secuencia (112), e1827. DOI: https://doi.org/10.18234/secuencia.v0i112.1827

cC Esta obra está protegida bajo una Licencia Creative Commons Atribución-NoComercial 4.0 Internacional. 
Palabras clave: historia del trabajo; trabajadores; sociedad; transformación social.

Abstract: Beginning with the acknowledgement of the significance of work in the history of humankind, this article explains the ways work has been conceived from the profound transformation of peasant societies to the slightly industrialized cities with which the Middle Ages ended, marking the start of Modernity. It explores the historical milestone of the discovery of America with the enormous contrasts between an advanced society and certain indigenous groups with their ancestral knowledge typical of their native cultures, which were slowly forced to adapt their knowledge to that of their colonizers and in some cases conquerors. It goes on exploring the contemporary thought in which intellectual work acquires a particular strength and social value and, lastly, it explains the concept of work in Latin America until the end of the 20th century.

Keywords: history of work; workers; society; social transformation.

Recibido: 26 de marzo de 2020 Aceptado: 14 de septiembre de 2020

Publicado: 28 de enero de 2022

\section{INTRODUCCIÓN}

$\mathrm{E}$ ste trabajo forma parte de la historia del ser humano desde su creación; para los antepasados se vinculó a penurias y necesidades, considerándose limitante de la libertad de los individuos, y como condición indispensable para formar parte del mundo de la "polis" como ciudadano. Por lo tanto, la sociedad antigua fue conservadora y sólo contempló la idea de libertad como el ocio y la contemplación, que subvaloró el trabajo manual ya que era exclusivo de los esclavos y campesinos, quienes, a pesar de representar la mayoría de la sociedad y cumplir una función productiva y necesaria, eran actividades no deseables. La Edad Media trajo consigo un cambio relevante, dándole un valor moral a las actividades relacionadas con el trabajo físico y subvalorando las actividades que no implicaban esfuerzo o sacrificio, tales como el comer- 
cio y la gobernanza, lo anterior gracias al preponderante papel que desempeñó la Iglesia católica en la definición del trabajo en el mundo.

El presente trabajo expone un recorrido histórico desde la Modernidad, y el impacto del descubrimiento de América en el cual se ponen en manifiesto los grandes contrastes de una sociedad avanzada y unos grupos indígenas que lentamente adaptaron sus saberes a sus colonizadores y en algunos casos conquistadores, se dan retrocesos en el trabajo retomando la esclavitud y el trabajo como sacrifico y penuria, pasando por el pensamiento contemporáneo, periodo en donde el trabajo intelectual cobra especial fuerza y valor social y en la actualidad se comienzan a esbozar nuevas formas de trabajo y ocupación; además, el descanso se convierte en un elemento fundamental de la sociedad moderna, el anhelo inalcanzable del asalariado relacionado con dedicar su vejez al descanso con comodidades y un salario que le permita terminar su vida dignamente.

Finalmente, se expone la transformación del trabajo bajo la sociedad latinoamericana del siglo $\mathrm{xx}$, con su mezcla de culturas que construyeron su propio concepto del trabajo y todas las preguntas con las que el siglo XXI comienza a cimentar los nuevos estudios laborales de la región.

\section{EL TRABAJO DESDE LA EDAD MODERNA HASTA LA CONTEMPORÁNEA}

Con el declive del modelo económico denominado feudalismo, hacia el siglo XII que culmina finalmente en el siglo xv, según Guerra (2011), a causa de la producción más eficiente de algunos bienes en las ciudades, y como consecuencia de las grandes migraciones de personas del campo hacia las nuevas y florecientes ciudades, transforman el concepto de riqueza antes concebido a partir de la posesión de tierras hacia la del dinero obtenido a través de dos fuentes principales: la primera el comercio, y la segunda los salarios pagados por el trabajo en las fábricas. En las zonas donde se desarrolló con fuerza el comercio, las asociaciones o agremiaciones de artesanos tomaron tanta fuerza que llegaron a intervenir en los gobiernos para defender sus propios intereses, convirtiéndose así en una nueva clase social acaudalada e influyente, pero sobre todo que comenzó a gozar de reconocimiento en las nuevas pequeñas sociedades urbanas, convirtiéndose en el preámbulo de la producción capitalista que expone tres principios: la propiedad privada, el trabajo asalariado y los primeros mercados. 
En este contexto es que se desarrolla el periodo denominado La Edad Moderna, comprendido entre el siglo XV y XVIII, el cual enmarca algunos hechos históricos relevantes, tales como el descubrimiento de América (1492) y la revolución francesa (1789), que dio inicio a la Edad Contemporánea. Uno de los grandes cambios que trajo consigo este periodo fue un nuevo concepto del trabajo en donde se considera una actividad valiosa y se desprecia el ocio, porque se relaciona con la pereza.

Con el descubrimiento de América ${ }^{1}$ vinieron consecuencias socioeconómicas y políticas importantes, ya que algunos sistemas de relaciones sociales como la esclavitud, en decadencia en Europa, toman fuerza en las colonias. Tras este hito histórico, en el siglo $\mathrm{xV}$, se presentaron contrastes sociales muy fuertes, ya que comenzaron a convivir sociedades primitivas dedicadas a labores como la cacería, la agricultura y la pesca junto con sus respectivos colonizadores, y en algunos territorios con conquistadores, quienes procedían de sociedades en donde la esclavitud y la servidumbre estaban íntimamente ligadas con el concepto de trabajo.

Es importante no desconocer que algunas culturas nativas de América ya habían alcanzado importantes desarrollos en sus relaciones productivas, y habían logrado -además de desarrollar sus actividades del sector primario, como ya se mencionó- desarrollar, aunque sutilmente, el intercambio. En este sentido, Florescano (2009) en su obra El origen del poder en Mesoamérica expone elementos de la cultura azteca en donde se destaca la repartición del trabajo, el manejo de los excedentes en la producción agrícola que llevaba al intercambio y la necesidad de protección de sus posesiones a partir de la construccion de fortalezas, que de algún modo se relacionan, por una parte, con la necesidad de un Estado protector y benefactor y, por otro, con la propiedad privada como elemento generador de riqueza.

Es, por lo anterior, que el descubrimiento de América por parte de los españoles, en el siglo xv, hace necesario que en Sudamérica se instaure un sistema de repartición de poblaciones indígenas, tratando de imponer la cultura europea en el nuevo continente, en donde imperó la encomienda, que pronto se fortaleció con la movilización forzada y la esclavitud de africanos trasladados forzosamente al continente americano con el objetivo de convertirse en la

${ }^{1}$ El descubrimiento de América ocurrió en 1492, con la llegada a América de una expedición dirigida por Cristóbal Colón por mandato de los reyes católicos (Isabel I de Castilla y Fernando II de Aragón). 
mano de obra que reemplazó a los indígenas sublevados para llevar a cabo el trabajo manual en las plantaciones.

Por otro lado, algunas comunidades religiosas hacia el siglo XVII, dentro de las que destacan los jesuitas (en Sudamérica, en particular), formaron comunidades a partir del concepto de "reducción" compuestas por aproximadamente 500 familias que desarrollaron relaciones sociales más de cooperación y trabajo común (Supervielle, s. a.):

[...] cada reducción tenía tierras que se consideraban comunes, las cosechas eran repartidas bajo la vigilancia de los padres. En segunda instancia se repartían lotes por familia para los cultivos de sus plantas alimenticias. El resto de la tierra seguía siendo comunal y de ella se retiraba la producción con la cual se pagaban los impuestos reales, para el mantenimiento de los misioneros y para el intercambio con otros productos necesarios que no eran producidos por la misión (p. 18).

En este sentido, la premisa general de los jesuitas fue mantener ocupados en laborales manuales a los indígenas y evitar así los tiempos de ocio, considerado por los religiosos como pecado. De esta forma, se evangelizaba a la población hacia la doctrina religiosa y se convertían los hombres en individuos sumisos a la misma. Finalmente, hacia mediados del siglo XVIII los jesuitas fueron expulsados de América, dejando en estas poblaciones grandes enseñanzas que pronto se convirtieron en los primeros eslabones de una incipiente industrialización originada a partir de los procesos y técnicas enseñadas por la comunidad religiosa.

Al mismo tiempo que ocurrió el descubrimiento de América, surgió un movimiento cultural en Europa Occidental denominado Renacimiento durante los siglos XV y XVI. Fue un periodo de transición entre la Edad Media y los inicios de la Edad Moderna. En el Renacimiento, los ahora llamados empresarios o dueños de las industrias y de los bancos cobraron fuerza no sólo económica, sino también escalaron socialmente, lo que obligó a redefinir el concepto de ética y virtud; como consecuencia, la Iglesia católica se dividió por el movimiento protestante, ahora el trabajo dignifica al hombre y la riqueza es el resultado de una vida laboriosa que Dios bendice (Guerra, 2011).

Durante los siglos XVI y XVIII al concepto de trabajo se le relacionó con la idea de "hacer trabajar" o lo que hoy se conoce como "emplear" y su respectiva contraprestación en dinero, que lentamente se transformó al compás 
de la movilización de las sociedades predominantemente campesinas hacia las grandes urbes, ahora en proceso de industrialización, al comienzo del siglo xx. Las organizaciones comenzaron a crecer extraordinariamente, al punto de tenerse que organizar jerárquicamente, y muchos de los artesanos que trabajaban en estas nunca tenían contacto con sus clientes, ya que trabajaban para un empresario o intermediario que vendía sus productos en otros mercados.

Las naciones europeas colonizadoras, posterior al descubrimiento de América, ahora en la Edad Moderna, se vieron beneficiadas por las riquezas provenientes de las colonias que comenzaron a movilizar mercancías en grandes volúmenes como nueva fuente de riqueza, lo cual fortaleció el comercio internacional. Así, comenzó a consolidarse una división de trabajo por países, lo cual transformó los procesos de producción interna de los mismos. Por un lado, países como España redujeron sus actividades productivas y comenzaron a consumir en su mayoría productos importados, mientras que países como Inglaterra se dedicaron a aumentar su producción hacia el exterior con el objetivo de abastecer a otros países y de esta forma hacer crecer sus dominios.

Según Guerra (2011), con la revolución industrial las industrias acapararon la mayor parte de la producción de las naciones europeas, la producción artesanal redujo su competitividad porque que no logró la producción en grandes volúmenes ni permitió la división del trabajo, imponiéndose de esta forma el trabajo asalariado en las ciudades. Según Superville (s. a.), al mismo tiempo que se dio la revolución industrial, hacia finales del siglo XVIII, se desató un fenómeno sociopolítico importante que inició la Edad Contemporánea, la revolución francesa; hecho que dio por terminado el feudalismo, inicialmente en Francia, luego en toda Europa.

La revolución industrial rescató la clase social antes marginada denominada la burguesía y la elevó en la escala social, al punto de convertirla en la clase social dominante en términos políticos y económicos: eran ya los dueños de los medios de producción, de la maquinaria y las empresas que generaban productos para toda la sociedad que había migrado del campo hacia las urbes.

Las fábricas organizaron su nueva maquinaria y trabajadores en edificios de grandes extensiones, bajo un nuevo orden jerárquico en el que la figura de poder se estableció en un jefe de taller; las nuevas máquinas mejoraron los tiempos de producción y la calidad de los productos, el trabajador ahora asalariado tenía un horario y unas labores claramente definidas. En 
este contexto, a mediados del siglo xVIII, el economista y filósofo británico Adam Smith, denominado "padre de la economía", en su obra La riqueza de las naciones afirmó que la fuente de toda riqueza es el trabajo y la división de trabajo es el medio para tal fin, que finalmente se traduce en la capacidad del individuo para obtener bienes y servicios de acuerdo con sus necesidades. En este sentido, el beneficio individual es al final el mismo beneficio del colectivo, y por tanto es desde el trabajo realizado por el obrero que este puede obtener bienes producidos por otros.

Hacia el siglo xIx, Marx en su obra El capital define el trabajo como una actividad exclusiva del hombre que permite el desarrollo del intelecto y lo diferencia de la bestia; diferenciando el trabajo cualitativo del llamado trabajo abstracto. Marx concibió el trabajo como una actividad natural del ser humano que le permite apropiarse de la naturaleza y transformarla para satisfacer sus necesidades infinitas, permitiéndole dar sentido a su vida, ya que se hace mediante la relación del hombre con la naturaleza. En este sentido, el trabajo es una actividad vital del hombre en el que transforma la naturaleza en productos, y se convierte en la base de apropiación y resultado del trabajo del hombre (Ventura, 2013).

La fuerza de trabajo fue para Marx la fuente de valor de la que finalmente se apropia la burguesía a través de "la plusvalía", concepto utilizado para exponer la explotación del modo de producción capitalista, y la fuente de acumulación de riqueza y capital medido en dinero y capacidad de producción de este.

Como consecuencia, el trabajo industrial cambia su concepción; que en el pasado se relacionó directamente ya sea con quién lo hacía o con quién lo solicitaba. Debido a la división del trabajo, el trabajo deja de ser concreto para convertirse en abstracto, ya que el trabajador logra ver el resultado tangible de su labor porque es parte de un proceso, además de la importancia que tiene el trabajo colectivo hasta entonces no identificado.

Lo anterior tiene como consecuencia el deterioro de la calidad de vida de la clase trabajadora, donde se destacan los horarios de trabajo de hasta 18 horas diarias, y otros abusos como la explotación infantil, criticados tajantemente por los seguidores del marxismo aún hasta el siglo xx (Supervielle, s. a.).

La importancia del trabajo colectivo también es identificada por las clases sociales trabajadoras, quienes se comienzan a agrupar y esto da como resultado las constituciones de los primeros sindicatos, inicialmente clandestinos y suprimidos en toda Europa, comenzando por Francia tras la revo- 
lución francesa, a través de la prohibición de todo tipo de asociación de los trabajadores, cuyos preceptos están materializados en la Ley Le Chapelier, nombre que se le dio a esta ley creada para tal fin. Dicha resistencia persistió hasta finales del siglo XIX en este país. En Inglaterra, por otro lado, a comienzos del siglo XIX se aceptó la libre asociación de los trabajadores, permitiéndoles negociar los salarios en colectivo y reconociendo los sindicatos como actores activos de trabajo.

Otro de los grandes cambios que trajo a la sociedad occidental la revolución industrial hacia mediados del siglo xix fue la inclusión de la mujer en las fábricas, dado que la producción de bienes aumentó de manera significativa y con esto surge la necesidad de mano de obra adicional, convirtiéndose esta en una obrera asalariada, en un comienzo como una labor secundaria de su vida, dada la especial preponderancia que aún para este momento histórico tiene para la mujer el trabajo reproductivo y el cuidado del hogar. $\mathrm{Y}$ es sólo hasta mediados del siglo $\mathrm{xx}$, posterior a la segunda guerra mundial, cuando la mujer se convierte en muchos casos en cabeza del hogar y muchas de ellas ven la necesidad de formar parte del mercado laboral, en especial en las fábricas manufactureras, y a partir de este momento comienzan con especial fuerza las grandes luchas por la igualdad de género y por supuesto involucran el ámbito laboral como uno de los pilares fundamentales de estas luchas por la igualdad de derechos (Scott, 2009).

Por su parte, Weber (2011), en La ética protestante concluyó que la filosofía protestante motivó el desarrollo del capitalismo; y a través de la ideología luterana, el espíritu tradicional altruista del ser humano deja de ser una premisa vital del mismo; asimismo, reconoce el comportamiento racional para lograr el éxito económico y ya no lo condena, por el contrario, lo alaba y anima para que sea ahora parte de la realización del hombre, sin dejar a un lado su desarrollo espiritual ahora alejado de la Iglesia romana.

El siglo xx trajo consigo el reconocimiento de los derechos de la clase trabajadora, desde el reconocimiento por el esfuerzo realizado y no por el producto tangible obtenido del mismo, la importancia del trabajo para la construcción de riqueza de las naciones y el carácter mercantil o transable de la mano de obra materializado en un salario recibido como contraprestación por la labor, no sólo para el trabajador, en determinados casos por un familiar dependiente del mismo en caso de muerte, además la obtención de días de descanso semanales y festivos, vacaciones remuneradas $y$, finalmente, la articulación de los derechos humanos con el trabajo (Supervielle, s. a.). 
Taylor, ${ }^{2}$ por su parte, hizo un gran aporte al concepto del trabajo a partir de sus análisis que se resumieron en una corriente denominada "la organización científica del trabajo", la cual parte de la visión antigua en la que el obrero es considerado un holgazán y el salario es un incentivo para hacer que su labor sea productiva, pero debe ser controlado en cada una de sus funciones (control de tiempos y movimientos) y dirigido desde una perspectiva científica. Así, la corriente taylorista convierte el trabajo en una labor asfixiante y alienante de acuerdo con Guerra (2011).

Friedman, ${ }^{3}$ por su parte, cuestionó el concepto de trabajo básico en el que se crea utilidad a través de este, ya que los animales también podrían hacerlo; incluye en este concepto, que el hombre transforma la naturaleza de acuerdo con su conveniencia y necesidades. Así mismo (Gorz, 1991), desde su escrito La metamorfosis del trabajo, considera que lo que hoy conocemos como trabajo es una invención de la modernidad, forjada en la revolución industrial.

En este sentido, las Naciones Unidas en 1969, en el Pacto Internacional de Derechos Económicos, Sociales y Culturales, definieron que el derecho al trabajo "Comprende el derecho de toda persona a tener la oportunidad de ganarse la vida mediante un trabajo elegido o aceptado libremente". ${ }^{4}$

Así, el trabajo considerado como derecho fundamental del hombre es necesario para llevar una vida digna, y todos los individuos tienen derecho a su plena y efectiva realización. Asimismo, es una actividad que le permite al hombre producir bienes y servicios para satisfacer sus necesidades de carácter material. Entonces, es un medio para obtener utilidad y bienestar al mismo tiempo, sin necesariamente considerarse trabajo exclusivamente al trabajo remunerado; también se contempla el trabajo en comunidad, el trabajo realizado por el trabajador independiente o a cuenta propia, trabajadores que prestan servicios a través de contratos, entre otros (Defensoría del Pueblo, 2005).

En esta misma línea, entendiendo el trabajo como derecho fundamental, este se encuentra ligado a otros derechos, o más bien a todos los demás

${ }^{2}$ Frederick Winslow Taylor (20 de marzo de 1856-21 de marzo de 1915) fue un ingeniero industrial y economista estadunidense, promotor de la organización científica del trabajo y es considerado el padre de la administración científica.

${ }^{3}$ Milton Friedman fue un estadista, economista e intelectual estadunidense de origen judío que se desempeñó como profesor de la Universidad de Chicago, nació en 1912 y falleció en 2006 en California.

${ }^{4}$ Pacto Internacional de Derechos Económicos, Sociales y Culturales. Naciones Unidas, Derechos Humanos, Oficina del Alto Comisionado, https://www.ohchr.org/sp/professionalinterest/pages/cescr.aspx 
derechos fundamentales. Siguiendo la Declaración de Viena (1993), todos los derechos fundamentales se encuentran interrelacionados, son universales e indivisibles. Bajo esta mirada, nuevamente se evidencia que el trabajo es un medio para alcanzar el desarrollo y satisfacer las necesidades del hombre.

Ahora bien, el concepto de trabajo antes del siglo xx se refirió a la simple producción de objetos a través de la transformación de la naturaleza en pro de la satisfacción de las necesidades humanas. Sin embargo, después de este siglo apareció un nuevo concepto de producción que no se limitó a la producción de bienes materiales, sino a una producción inmaterial que incluye servicios tales como salud y educación, entre otros. Otro cambio relevante a destacar es el trabajo como actividad intelectual, y no necesariamente implicando un desgaste físico del individuo, una combinación de ambos aspectos. Lo anterior, también permeó en la sociedad alterando las relaciones sociales, tal como lo indica Garza (2000) en su escrito "Los límites del concepto de trabajo clásico restringido", en donde intervienen patrones, asalariados, clientes y usuarios, que son nuevas denominaciones sociales antes no contempladas.

En síntesis, el concepto de trabajo es heterogéneo aún en tiempos recientes, y se puede definir a partir de dos postulados teóricos: el primero corresponde a la visión neoclásica en la que el único trabajo contemplado es el asalariado, en el que el precio del trabajo es el salario. El otro es el marxista, que considera al trabajo como toda actividad relacionada con la generación de riqueza en la sociedad. Esta segunda visión del trabajo es la que desata el interés de la sociología, pero más específicamente de la sociología del trabajo. Y una tercera visión contempla una combinación de la primera y la segunda, definiendo el trabajo como un medio para alcanzar la plenitud del hombre y al mismo tiempo los bienes y servicios que le permiten satisfacer sus necesidades materiales.

La sociedad en la actualidad se encuentra viviendo un proceso llamado postindustrial, en donde la propiedad privada pasó de ser el centro de atención por la adquisición de conocimiento; la transformación de las economías concentradas en la producción de bienes ahora también productoras de servicios, tal como lo demuestra Daniel Bell en su obra El advenimiento de la sociedad post-industrial (Guerra, 2011).

Guerra (2011), considera que el punto de partida de esta nueva sociedad se dio a mediados del siglo $\mathrm{xx}$, periodo en el que el trabajo agrícola se redujo considerablemente y el trabajo asalariado ya no sólo se concentró en empresas productoras de bienes materiales, sino que ahora se volcaron a solu- 
cionar las necesidades del individuo a través de la generación de servicios. Un invento que revolucionó la sociedad y especialmente el trabajo fue el computador personal, que unido al desarrollo de la red Internet, llevó el mercado de casi todos los bienes y servicios a otro espacio inexplorado hasta este siglo.

En esta misma línea, Zapata (2007) define la sociedad actual como una sucesora de la sociedad de la producción denominada la sociedad del conocimiento; definida como una sociedad en donde las personas deben usar su capacidad de reflexión y observación en el quehacer diario de sus trabajos. Lo anterior, reconoce la importancia de los desarrollos taylorianos adaptados a los nuevos retos, con nuevos modelos de organización del trabajo tomados de los japoneses, en donde las jerarquías y los grandes espacios de trabajo se reevalúan, dado que los trabajadores adquieren más autonomía sobre sus responsabilidades, mismas que ya no se miden por su destreza manual sino por su capacidad mental.

El proceso de transformación de las sociedades contemporáneas ha sido desigual en las diferentes sociedades, algunas han avanzado rápidamente hacia los procesos de postindustrialización, sin embargo, otras continúan en procesos de industrialización incipiente con la atenuante de su inmersión en un mundo globalizado en donde se deben adaptar los bienes y servicios a las necesidades del mundo entero. Por lo anterior, es necesario analizar por separado estos diferentes procesos teniendo presente las grandes diferencias ya mencionadas; $y$, es por esto, por lo que en el siguiente apartado nos concentramos en describir los procesos de transformación laboral en el territorio de interés de esta investigación, que es Latinoamérica.

\section{LA TRANSFORMACIÓN LABORAL EN LATINOAMÉRICA, SIGLO XX}

América Latina ingresó en el mercado mundial a comienzos del siglo xx, a partir del desarrollo de sus primeras formas de capitalismo dependiente, imponiendo leyes contra las tierras improductivas, haciendo expropiaciones masivas de tierras y reubicando la mano de obra de miles de trabajadores del sector minero y del sector agrícola hacia las nacientes industrias. Es este proceso el que se convierte en los primeros pasos hacia el desarrollo de una nueva clase social -que asumirá características particulares a lo largo de los años que siguen-: el trabajador asalariado. 
Además de las migraciones internas que se producen, principalmente desde el campo hacia las ciudades, debe reconocerse que se adiciona un flujo hacia América de inmigrantes europeos, provenientes en su gran mayoría de España, Portugal e Italia, ubicándose muchos de ellos en la zona atlántica por su cercanía con el mar y transformando la estructura social de la zona (UNLA, 2017). Los nuevos habitantes de América Latina, además de reestructurar los tejidos sociales de la región, trajeron consigo nuevas formas de organización y asociación; las primeras organizaciones obreras estaban caracterizadas por una carencia de organización, lo cual no les permitía desarrollar una estructura a nivel nacional ni mucho menos un aparato burocrático consolidado.

Así, hacia comienzos del siglo xx los sindicatos empezaron a aparecer lentamente en algunos sectores, especialmente en aquellos donde había grandes concentraciones de trabajadores, tales como en ferrocarriles, la construcción de puertos y la extracción minera. Las principales razones de inconformidad de los obreros estaban relacionadas con las condiciones precarias de sus trabajos en relación con sus salarios, causales directas del deterioro de sus condiciones de vida y de salud:

[...] durante la década de 1920 comienza a desplegarse un proceso de resistencia casi sin precedentes, que tuvo como protagonistas a los trabajadores de las economías de enclave agrícola. Enlazando con la tradición de lucha campesina, pero con una representatividad sectorial más amplia de sus líderes, y como continuidad de las huelgas de mineros y de petroleros en Chile, Bolivia y Venezuela en la década anterior, se desarrollaron huelgas de alto impacto que conmocionaron las estructuras de dominación locales (UNLA, 2017, p. 6).

Por lo anterior, la organización del trabajo se caracterizó por la fortaleza de unos modelos jerárquicos basados en mecanismos de control y autoridad sobre los trabajadores, contrarios a los modelos estadunidense y europeo concentrados en la división del trabajo, la reducción de los tiempos ociosos, el aumento de la productividad y la reducción de costos de producción.

El creciente desarrollo de las economías latinoamericanas del siglo xx fomentó también la vinculación masiva de la mujer en el mercado laboral de la región, aunque de manera desigual en los diferentes países, especialmente en sectores que requerían mano de obra poco calificada y de bajo costo, como, por ejemplo, el sector agrario. Para el caso de la incorporación de la mujer en otros sectores, como el manufacturero, se dio hacia finales del siglo $\mathrm{xx}, \mathrm{y}$ 
está fuertemente vinculada con el aumento en las tasas de escolaridad de la población y las nuevas necesidades de producción que fueron surgiendo en el proceso de incorporación de las economías regionales en el mercado mundial (Maubrigades, 2018).

Este proceso de mundialización de la economía, en donde se marca la división del mundo hacia mediados del siglo $\mathrm{xx}$, en particular después de las guerras mundiales, América Latina se dedica a la producción de bienes primarios y manufactureros básicos, dejando a los países desarrollados el papel de la producción de capital; es decir, de maquinaria. Es así como surge el modelo denominado "sustitución de importaciones", que fomentó la producción interna de bienes primarios y algunos bienes manufacturados básicos que pretendían suplir las necesidades de bienes de consumo al interior de Latinoamérica y la importación únicamente de bienes de capital, con el propósito de fortalecer al interior de estos países su capacidad productiva y fomentar su incipiente industria (Vázquez, 2017).

En los diferentes países latinoamericanos los modelos de sustitución de importaciones fueron aplicados de diferentes formas, tal como lo indican Catalano y Novick (citado en Garza, 2000). Por ejemplo, en Argentina, la organización científica del trabajo se orientó hacia el control de los trabajadores a partir de mecanismos de control en una estructura jerárquica de tipo piramidal; asignación de labores en puestos fijos, resultado de acuerdos colectivos.

En el caso de México, a partir de la revolución mexicana a comienzos del siglo xx (1910), el modelo laboral se concentró en tres frentes: el primero, las políticas laborales de salarios y empleos; el segundo, las discusiones tripartitas (Estado, trabajadores y empresarios); y, finalmente, los salarios llamados indirectos o seguridad social adicional al salario nominal.

En Brasil, por su parte, las industrias se concentraron en la división del trabajo a partir del establecimiento de pasos y procesos, sin dejar de lado la fuerte presencia del Estado en la definición de criterios de asignación de salarios, estructura de los contratos y seguridad social, al igual que en el resto de América Latina.

En lo concerniente a los procesos de modernización tecnológica, hasta mediados de la década de los ochenta en la mayoría de los países de la región, se consideró innovación al simple hecho de sustituir máquinas desgastadas por unas nuevas con algunos valores agregados adicionales. También es el momento en el que se comienzan a aplicar algunos elementos de un nuevo modelo considerado el "modelo japonés", el cual consistió en la organización 
del trabajo en grupo aplicando la premisa "just in time", reduciendo inventarios a partir de la producción sobre pedido en corto tiempo, simplificando los procesos pero conservando altos estándares de calidad (Novick, 2000).

Al mismo tiempo, con los aumentos de productividad alcanzados a partir del nuevo modelo de producción, las relaciones laborales se flexibilizaron desarrollando una nueva institucionalidad, tal como lo indica Garza (2000). A finales del siglo xx aparece la corriente económica llamada neoliberalismo que retoma los preceptos clásicos de la economía, en la que se autorregulan los mercados limitando el accionar del Estado a la simple regulación de estos.

La flexibilización laboral se enlazó con una nueva relación de los factores trabajo y capital, dejando en este nuevo contexto el factor trabajo y, en particular, los salarios a las fuerzas del mercado, considerando el trabajo como un mercado que se ajusta por sí solo sin necesidad de ningún tipo de intervención estatal. Así, los conceptos de oferta y demanda se ajustan adaptándose a este mercado y permitiendo la distribución y asignación de salarios y puestos de trabajo.

En esta misma línea, si la oferta de trabajo, es decir, la cantidad de individuos interesados en trabajar, excede la demanda o los puestos de trabajo disponibles, esto resultaría en unos salarios más bajos. Asimismo, el tamaño de la población es el que determina la tasa de participación y, por lo tanto, la oferta de trabajo de los individuos, la cual es una decisión de cada persona y depende de su interés en descansar o trabajar. También se supone que la oferta de trabajo cumple la ley de rendimientos marginales decrecientes, es decir que después de una determinada cantidad de trabajadores, contratar uno adicional generará un decrecimiento en la producción; asimismo, que los trabajadores poseen información completa del mercado, tal como son los valores de los salarios, horarios, tipo de trabajo, etc., lo que les permite tomar decisiones racionales en las que balancean sus tiempos de ocio y trabajo (Garza, 2000).

Garza (2000) considera también que los dueños de las empresas que demandan trabajo tienen conocimiento del mercado y son agentes racionales, además, los mercados son competitivos sin ningún poder de mercado, ni de su parte ni de los trabajadores que contrata.

En este orden de ideas, los salarios nominales se vincularon directamente a los cambios en el nivel general de precios con el fin de mantener el valor del salario real en el tiempo, o la capacidad adquisitiva de los trabajadores. No obstante, no fue aplicado en todos los países latinoamericanos ni en todos los sectores productivos. 
En este nuevo contexto, se gesta un nuevo modelo productivo en el que los países latinoamericanos se abren a las economías internacionales y al proceso de globalización; asimismo, se eliminaron muchas de las negociaciones colectivas entre empresa, Estado y trabajadores, ya que fueron privatizadas la mayoría de las empresas productivas de los Estados.

Los Estados latinoamericanos, hacia finales del siglo $\mathrm{xx}$, desarrollaron instituciones encargadas de regular el trabajo y los conflictos entre los trabajadores y los empleadores, y dejaron de intervenir directamente sobre el tipo de contratación y sobre la producción de los sectores, con el objetivo de facilitar la entrada y salida del mercado de los trabajadores a los puestos de trabajo, lo que en otras palabras es la denominada flexibilidad laboral, retomando las ideas ya mencionadas de los preceptos clásicos de la economía.

En Latinoamérica en los años setenta se dieron dictaduras militares, que se convirtieron después de dos décadas en consolidados gobiernos civiles. En particular, el caso de Chile llama la atención porque representó la entrada del neoliberalismo en esta nación de manera violenta y abrupta, a partir del golpe militar dado en 1973 por Augusto Pinochet derrocando el gobierno comunista de Salvador Allende, posibilitando la economía de mercado a partir de la liberalización de la economía y relevando el papel preponderante del Estado en la producción de bienes y servicios, ideas fomentadas por la famosa escuela de Chicago. Es así como los gobiernos, ahora, dedicaron su accionar durante las últimas décadas del siglo pasado hacia el control de la inflación y la tasa de cambio, es decir, a los flujos de dinero, alejándose así de la producción de bienes y servicios o de la denominada economía real, bajo el supuesto neoliberal que asume que, una vez que son ajustadas las variables macroeconómicas, los sectores productivos funcionan sin necesidad de intervenciones de ningún tipo (Espinoza, 2003; Garza, 2000).

También, el modelo neoliberal trajo consigo una reducción de la calidad de vida de la clase trabajadora, y un ejemplo de esto es la subcontratación de los trabajadores que articulan las empresas productivas con otras empresas oferentes de mano de obra. Igualmente, se evidencia la creación de mediana industria con bajos niveles de productividad y calidad, explicado en muchos casos por los bajos niveles de uso de la tecnología. Por otro lado, se hicieron reformas a los sistemas de seguridad social, a la contratación colectiva y a las leyes del trabajo.

Martha Novick expone la idea de que la industrialización en Latinoamérica fue tardía respecto a los países europeos (Garza, 2000). Una de las 
razones que sustentan esta afirmación apunta a las políticas de sustitución de importaciones de los gobiernos latinoamericanos basadas en modelos de subsidios y proteccionismo de las industrias nacionales, las cuales fortalecieron el desarrollo industrial al interior de los diferentes países, aislándolos de los criterios de productividad del resto de las naciones, debido a sus mercados cerrados para el ingreso de bienes y servicios producidos fuera de su producción local.

En Latinoamérica, como resultado de las grandes luchas sociales del siglo xx, se permitió la reflexión sobre el impacto de los procesos de industrialización y su inclusión en la cotidianidad del individuo. En este sentido, las consecuencias fueron las nuevas formas de organización del trabajo ampliamente criticadas. Hacia mediados de los ochenta se flexibilizaron los contratos laborales y el Estado dejó de desempeñar un papel activo en la producción de los países de América Latina; por su parte, el cambio institucional permitió la desregularización de la relación laboral o del contrato laboral, permitiendo a los empleadores usar diferentes tipos de contratos de trabajo que ahora también se llamaron prestaciones de servicios bajo subordinación (Richter, 2011).

Asimismo, en las últimas décadas del siglo xx se redujeron las organizaciones sindicales que se habían fortalecido en las instituciones del Estado, como resultado de los procesos de privatización de bienes y servicios provistos por el sector público.

Grandes críticas y discusiones se dieron alrededor de esta serie de cambios estructurales de la sociedad, y en particular del concepto de trabajo, dentro de las que se destaca el institucionalismo; corriente que discutió con los neoclásicos en razón a su desprecio por las instituciones encargadas de la normalización del mercado de trabajo.

En el panorama descrito nace la corriente ideológica latinoamericana denominada la Sociología del Trabajo en América Latina, como análisis disciplinar específico encargado de estudiar el cambio del modelo productivo clásico, la organización social del trabajo y los efectos de la globalización en las formas capitalistas de producción. Además, se consolidó la Asociación Latinoamericana de Sociología del Trabajo (ALAst), la cual desde su constitución en los ochenta ha desarrollado tres líneas de investigación:

1. Incorporación de nuevas tecnologías en América Latina y cómo en esta región la mayor parte de los procesos productivos continuaron siendo intensivos en el uso de mano de obra. 
2. Nuevas formas de organización del trabajo, el empoderamiento del trabajador con la empresa en pro de la productividad de esta; sin embargo, los empresarios no simpatizaron con la negociación colectiva, ya que las decisiones estratégicas de la empresa seguían en sus manos.

3. Flexibilización laboral y la pérdida de los derechos laborales en muchos casos.

A partir de los grandes cambios estructurales que desató la apertura de los mercados en Latinoamérica de mediados en los años ochenta, surgió un movimiento denominado Nuevos Estudios Laborales, el cual analizó elementos como la flexibilización laboral, los cambios tecnológicos en la producción y las nuevas formas de producción, entre otros (Garza, 2000).

Esta nueva corriente ideológica de estudios laborales expuso la teoría de la dependencia, que fue una tendencia mundial de la segunda mitad del siglo $\mathrm{xx}$, en donde se trasladaron los procesos productivos que implicaban grandes contrataciones de mano de obra poco calificada hacia los países subdesarrollados. Sin embargo, esta teoría no fue suficiente para explicar la dependencia de los países industrializados que se acentuó durante la época y sus efectos sobre los mercados laborales en los países subdesarrollados.

Garzo (2000) expuso que los estudios sociológicos del trabajo en un principio se concentraron en estudiar los procesos que requerían los diferentes trabajos y el análisis del trabajo desde el interior de las organizaciones, dejando de lado los análisis sobre los mercados de trabajo, sus asimetrías e imperfecciones.

Tal como Guerra (2011) lo indica, la misma globalización ha hecho que muchas de las temáticas abordadas por la ciencia sean nuevas, pero la esencia es la misma. Un hecho importante a destacar es que la sociología del trabajo en Latinoamérica ha abordado temas y líneas de investigación con origen en otros espacios geográficos, dentro de los que se identifican las líneas tanto francesa como anglosajona.

La reflexión sobre temas laborales hasta los años ochenta en el mundo se concentró en la organización de las industrias (Richter, 2011), y tal vez el punto de partida de tal interés en la materia es la investigación sobre la planta de la Western Electric, en Hawthorne, realizada por el sociólogo Elton Mayo en el periodo de 1923 a 1932. Esta fue la que sentó las bases de la sociología empresarial, en el que se abren las empresas a los aportes de la ciencias sociales para mejorar su funcionamiento y a este tipo de estudios más adelante se les denomina el "enfoque adaptativo" (Guerra, 2011). 
Como resultado de los estudios de esta corriente de la sociología, se encontró que el único tipo de contratación existente, hasta los años ochenta, era el modelo asalariado en el que el trabajador recibía un salario fijo por realizar un trabajo a tiempo completo en una empresa.

Muchas investigaciones analizaron la evolución del trabajo a partir de la división y su estructura y las estructuras de las organizaciones, pero algo que llama la atención es la identificación de la diferencia entre empleo y trabajo que se analizará más adelante (Prieto, 2007). Así, en 1946, la American Sociological Association se reunió para analizar los avances en la sociología industrial, también llamada de las organizaciones por Max Weber en 1969, quien planteó que, a partir del tipo de dominación burocrática materializada en reglamentos, jerarquía de funciones, entre otros, se establece una relación de subordinación (Carballo, 2011).

Por su parte, el Fondo de Cultura Económica (FCE) en el año 2000 sistematizó algunos resultados de la investigación en estudios laborales en América Latina, que permitió ampliar el concepto de trabajo y sociología del trabajo; tales como los efectos del neoliberalismo en la economía, pero especialmente en los mercados laborales que pronto desmejoraron la calidad de vida de los trabajadores (Garza, 2000).

Finalmente, los estudios del trabajo desarrollados a la luz de la sociología del trabajo han analizado los cambios de la sociedad del siglo xx, especialmente a partir de sus efectos sobre el trabajo reconocido, con matices diferentes en los casos de las sociedades capitalistas desarrolladas y las subdesarrolladas. La relación social llamada trabajo se puede analizar a partir de los diversos modelos de producción en los contextos de cada sociedad (Carrasquer, Torns, Tejero, Romero, 1998).

\section{CONCLUSIONES}

El concepto de trabajo ha evolucionado junto con la historia del ser humano. La sociedad antigua fue conservadora y dio mucho valor al ocio y la contemplación y despreció el trabajo manual, ya que era exclusivo de los esclavos y campesinos, quienes, a pesar de representar la mayoría de la sociedad y cumplir una función productiva y necesaria, eran actividades no deseables. Ya en la edad media se invirtieron los papeles del ocio y el trabajo gracias al prepon- 
derante papel que desempeñó la Iglesia católica en la definición del trabajo en el mundo.

Durante la modernidad se transforma radicalmente el concepto del trabajo, pasando de ser relacionado con penurias y sacrificios, a ser considerado una actividad valiosa y fundamental del hombre, hecho que aún en la actualidad es valorado en estos términos.

El descubrimiento de América condujo al mundo a consecuencias socioeconómicas importantes. Algunos sistemas como la esclavitud, en decadencia en Europa, fundamentaron la fuerza de trabajo en las colonias americanas, en donde comenzaron a convivir sociedades primitivas dedicadas a labores como la cacería, la agricultura y la pesca, junto con nuevos habitantes conquistadores quienes procedían de sociedades en donde la servidumbre estaba ligada al concepto de trabajo, replanteando en América el concepto de trabajo propio de las culturas precolombinas.

Las naciones europeas, posterior al descubrimiento de América, se incorporaron a un nuevo momento histórico llamado la Edad Moderna, siendo beneficiadas por las riquezas provenientes de las colonias que comenzaron a movilizar mercancías en grandes volúmenes como nueva fuente de riqueza, lo cual fortaleció el comercio internacional. Así, comenzó a consolidarse una división de trabajo por países, lo cual transformó los procesos de producción interno de los mismos.

Es importante reconocer que las culturas nativas de América, antes de la llegada de los españoles al territorio, ya habían alcanzado importantes desarrollos en sus relaciones productivas, y habían logrado además de desarrollar sus actividades del sector primario, la extracción y posesión de metales preciosos como base de sus posesiones valiosas.

La revolución industrial rescató la clase social antes marginada denominada la burguesía y la elevó en la escala social, al punto de convertirla en la clase social dominante en términos políticos y económicos: ahora son los dueños de los medios de producción, de la maquinaria y las empresas que generan productos para toda la sociedad, los que habían migrado del campo hacia las urbes.

La importancia del trabajo colectivo también es identificada por las clases sociales trabajadoras, que se comienza a agrupar y da como resultado las constituciones de los primeros sindicatos, inicialmente clandestinos y suprimidos en toda Europa, comenzando por Francia tras la revolución francesa. 
En el siglo xIx, Marx expuso su idea del trabajo como una actividad exclusiva del hombre que permite el desarrollo del intelecto y lo diferencia de la bestia, diferenciando asimismo el trabajo cualitativo del llamado trabajo abstracto. Esto convirtió al trabajo en una actividad vital del hombre en el que este transforma la naturaleza en productos y se convierte en la base de apropiación y resultado del trabajo del hombre.

América Latina ingresó al mercado mundial a comienzos del siglo xx, a partir del desarrollo de sus primeras formas de capitalismo dependiente, imponiendo leyes contra las tierras improductivas, haciendo expropiaciones masivas de tierras y reubicando la mano de obra de miles de trabajadores del sector minero y del sector agrícola hacia las nacientes industrias. Es este proceso el que se convierte en los primeros pasos hacia el desarrollo de una nueva clase social, que asumirá características particulares a lo largo de los años que siguen: el trabajador asalariado.

En el siglo $\mathrm{xx}$, los sindicatos aparecen en Latinoamérica lentamente en algunos sectores, especialmente en aquellos donde había grandes concentraciones de trabajadores, tales como en ferrocarriles, en la construcción de puertos y en la extracción minera. Las principales razones de inconformidad de los obreros fueron la causa de las condiciones precarias de sus trabajos en relación con sus salarios, causales directas del deterioro de sus condiciones de vida y de salud.

Las economías de la región crecieron en el siglo xx, hecho que generó la necesidad de contratar más mano de obra, especialmente en sectores que requerían bajos niveles de calificación, como el sector agrario, lo cual desencadenó la primera vinculación masiva de la mujer en el mercado laboral de la región, aunque de manera desigual en los diferentes países.

La incorporación de la mujer en el mercado laboral se dio hacia finales del siglo xx, y está fuertemente vinculada con el aumento en las tasas de escolaridad de la población y las nuevas necesidades de producción que fueron surgiendo en el proceso de incorporación de las economías regionales en el mercado mundial.

Hacia mediados del siglo xx, América Latina se dedica a la producción de bienes primarios y manufactureros básicos, dejando a los países desarrollados el papel de la producción de capital, es decir, de maquinaria, dando origen al modelo de sustitución de importaciones. Ello fomentó la producción interna de bienes primarios y algunos bienes manufacturados básicos que pretendían suplir las necesidades de bienes de consumo al interior de 
Latinoamérica y la importación únicamente de bienes de capital, con el objetivo de fortalecer al interior de estos la industria nacional.

A finales del siglo xx aparece la corriente económica del neoliberalismo que retoma los preceptos clásicos de la economía, en la que se autorregulan los mercados limitando el accionar del Estado a la simple regulación de estos. La flexibilización laboral se relacionó con una nueva relación de los factores trabajo y capital, dejando en este nuevo contexto el factor trabajo y en particular los salarios a las fuerzas del mercado, considerando el trabajo como un mercado que se ajusta por sí solo sin necesidad de ningún tipo de intervención estatal.

En este nuevo contexto, se gesta un nuevo modelo productivo en el que los países latinoamericanos se abren a las economías internacionales y al proceso de globalización; asimismo, se eliminaron muchas de las negociaciones colectivas entre empresa, Estado y trabajadores.

Los Estados latinoamericanos, hacia finales del siglo $\mathrm{xx}$, desarrollaron instituciones encargadas de regular el trabajo y los conflictos entre los trabajadores y los empleadores, y dejaron de intervenir directamente sobre el tipo de contratación y sobre la producción de los sectores, con el objetivo de facilitar la entrada y salida del mercado de los trabajadores a los puestos de trabajo, lo que en otras palabras es la denominada flexibilidad laboral, retomando las ideas ya mencionadas de los preceptos clásicos de la economía.

En el panorama descrito, se desarrolló la corriente ideológica llamada Sociología del Trabajo en América Latina, como análisis disciplinar específico encargado de estudiar el cambio del modelo productivo clásico, la organización social del trabajo y los efectos de la globalización en las formas capitalistas de producción.

A partir de los grandes cambios estructurales que desató la apertura de los mercados en Latinoamérica de mediados en los años ochenta, surgió un movimiento denominado Nuevos Estudios Laborales, que analizó elementos como la flexibilización laboral, cambios tecnológicos en la producción y las nuevas formas de producción, posibilitando la entrada de la región al presente siglo con nuevos retos en torno a su definición de trabajo y lo que este significa para el hombre y su autorrealización. 


\section{LISTA DE REFERENCIAS}

Carballo, P. (2011). Hacia un reposicionamiento de los estudios del trabajo: el desarrollo de la sociología del trabajo y sus principales debates. Anuario de Estudios Centroamericanos, 37, 307-325. Recuperado de https://revistas.ucr.ac.cr/index.php/ anuario/article/view/1131

Carrasquer, P., Torns, T., Tejero, E. y Romero, A. (1998). El trabajo reproductivo. Papers. Revista de Sociología, 55, 95-114. Dor: https://doi.org/10.5565/rev/papers.1934

Declaración de Viena (1993). Consejo de Europa. Declaración de Viena, 9 de octubre de 1993 [traducción del texto francés]. Revista de Instituciones Europeas, 20(3), 1085-1095. Recuperado de http://www.cepc.gob.es/publicaciones/revistas/ revista-de-instituciones-europeas/numero-20-septiembrediciembre-1993/consejo-de-europa-declaracion-de-viena-9-de-octubre-de-1993-1

Defensoría del Pueblo (2005). Contenido y alcance del derecho individual al trabajo. Marco para la evaluación de la política pública del derecho al trabajo desde una perspectiva de derechos humanos. Colombia: Defensoría del Pueblo. Recuperado de http://www. corteidh.or.cr/tablas/r26115.pdf

Espinoza, M. (2003). Trabajo decente y protección social. Santiago de Chile: отт/Central Unitaria de Trabajadores de Chile. Recuperado de http://www.escuelasindical. org/blog/wp-content/uploads/2006/11/trabajo-decente-oit.pdf

Florescano, E. (2009). Los orígenes del poder en Mesoamérica. México: Fondo de Cultura Económica.

Garza, E. de la (coord.) (2000). Tratado latinoamericano de sociología del trabajo. México: El Colegio de México/Flacso/UAm/FCE. Recuperado de http://www.flacsoandes. edu.ec/libros/digital/51932.pdf

Gorz, A. (1991). Metamorfosis del trabajo. Madrid: Editorial Sistema.

Guerra, P. (2011). Sociología del trabajo. Montevideo: Kolping Uruguay. Recuperado de http://www.kolping.org.uy/sites/default/files/contenidos/publicaciones/archivos/Kolping_Libro SDT_dig.pdf

Maubrigades, S. (2018). Mujeres y desarrollo en América Latina durante el siglo xx. Tasas de actividad, niveles de desarrollo económico y modelos productivos. Revista Uruguaya de Historia Económica, 8(14), 9-33. Recuperado de http://www. audhe.org.uy/images/stories/upload/Revista/Revista_14/silvanamaubrigades_ rev14_2018.pdf

Novick, M. (2000). La transformación de la organización del trabajo. En E. de la Garza Toledo, Tratado latinoamericano de sociología del trabajo (pp. 123-147). México: Fondo de Cultura Económica. 
Prieto, R. C. (2007). Del estudio del empleo como norma social al de la sociedad como orden social. Papeles del CEIC, 1. Recuperado de http://dialnet.unirioja.es/ servlet/articulo?codigo=2254038\&info=resumen\&idioma $=$ SPA

Richter, J. (2011). El concepto ampliado de trabajo: los diversos trabajos. Gaceta Laboral, 17, 169-189.

Scott, J (2009) La mujer trabajadora en el siglo XIX. Buenos Aires. Recuperado de https://www.fhuc.unl.edu.ar/olimphistoria/paginas/manual_2009/docentes/ modulo1/texto3.pdf

Supervielle, M. (s. a.). La evolución del concepto de trabajo y su relación con los derechos humanos. Recuperado de https://www.gub.uy/ministerio-trabajo-seguridad-so$\mathrm{cial} /$ comunicacion/publicaciones/evolucion-del-concepto-trabajo-su-relacion-derechos-humanos

UNLA (2017). Apuntes para una breve historia del movimiento obrero en América Latina. En Atlas histórico de América Latina y el Caribe (pp. 532-551). Buenos Aires: Centro de Estudios de Integración Latinoamericana. Recuperado de http://atlaslatinoamericano.unla.edu.ar/assets/pdf/abordajes/movimiento-obrero.pdf

Vázquez, L. (2017). Revisión del modelo de sustitución de importaciones: vigencia y algunas reconsideraciones. Economía Informa, 404, 5-16. DoI: https://doi. org/10.1016/j.ecin.2017.05.008

Ventura, E. (2013). El concepto de trabajo en el joven Marx: enajenación, autorrealización, socialismo. Revista de Humanidades, 5(2), 20-36. Recuperado de http://ri.ues. edu.sv/id/eprint/996/

Weber, M. (2011). La ética protestante y el espíritu del capitalismo. México: FCE.

Zapata, F. (2007). Relaciones laborales, desarrollo y democracia en el siglo XxI. Estudios Sociológicos, 15(44), 437-452. Recuperado de http://www.jstor.org/stable/40420465 